\title{
The Effects of the Qualitative Parameters of Internal Auditing Works on the Preferences of Investment Funds' Analysts
}

\section{Ibrahim Mert}

\section{Abstract}

This article documents the direct relation between the internal auditing reports that are revealed to the investors with facts of fraud in an entity and investor confidence for investing such companies. The contents of the internal auditing reports, which have been prepared specifically in response to the fraud signal in a company, provide evidence that there is a considerable correlation.

This paper argues that the observed correlation fluctuates depending on the contents, independence, and objectivity of an internal auditing report. The strength of the established correlation varies according to the provided confidence to investors. With the said confidence, the investors decide to retain their investments in a company, to invest new funds in a company, not to invest any funds, or to withdraw invested funds from a company.

The flow of the preferences of investment fund experts is affected:

(i) If the internal auditing process and report is concluded by experienced auditors;

(ii) If the internal auditing work is processed objectively;

(iii) If the internal auditors act independently during the auditing process.
Keywords: Internal auditing, internal control systems, auditing measures,

Jel: M40, M41, M42

\section{Introduction}

It has been established for years that internal auditing activity is one of the most crucial governing functions. It is accepted that, in modern management, a management function is clearly different from the detection of the weak points of fraud actions. As Dunn (1996), Vincent (at al. 1999), Guredin (1996) and Millichamp (2002) emphasize that internal control systems should focus on all activities of an organization. The detection in a company is surely important for the managers, but it is more important for the shareholders of the company because they are, mostly, far from the company and they are not able to observe if the assets of the company are kept in a safe environment and utilized according to the procedures defined earlier. More than that, they need to be sure that the defined procedures are strong enough or should be strengthened because of weak points.

This document analyzes the evaluation of the qualitative criteria of the internal auditing process from the angle of the shareholders. Coram, Ferguson, and Moroney (2008) say that there has been extensive research on 


\section{Articles}

the importance of an internal audit function as part of an effective corporate governance structure. Studies of Abbott et al. (2000) and Beasley et al. (2000) reveal that there is an association between corporate governance and fraud activities. More than discussing whether internal auditing is important or not as a governing tool, this paper assesses how the shareholders value the internal auditing process from the starting point to the final auditing report. How the shareholders evaluate the experience, objectivity, independence of the auditors, and the contents of the internal auditing report is an issue of considerable importance. Abbott et al. (2007) found from the survey that with strong audit governance, a company does not need external auditing services for routine internal auditing works.

This paper assessed their hypothesis. The total number of 143 copies of the questionnaire was distributed to the employees who work in 19 different investment funds located in Istanbul, Turkey and out of 143 copies, 66 responses were returned. During the examination of the answers in the returned copies, different statistical tools have been used for some analysis and tests such as descriptive statistics, chi-square, etc. The perceptions of the respondents have been reflected in the answers, and the test results documented that there is no significant difference from the angles of the investors about the evaluation of the internal auditing process.

In conclusion, the evaluation of the investors established that the qualitative points of an internal auditing process are considered as a required specification of an internal auditing process in the eyes of investors.

This paper has been organized on the basis of the following structure: 1. Independent and objective internal auditing reports (IAR), 2. Background, data collection, and estimation methodology, 3. Empirical findings and Conclusion.

\section{Independent and objective internal auditing reports (IAR)}

In broad terms, fraud means types of "disorders", "irregularities", "weaknesses", or "frauds" that contain the different types of deficiencies in accounts, deviations on the ratios, disturbances on operations and even frauds on assets and agreements.

The meaning of disorders or irregularities is any deviations from the legal background, regularity or conformity and also the nonobservance of the stipulations or procedures of a company. Deficiencies, deviations, and disturbances are non-observances of the company's rules and violating the established procedures.

The concept of fraud has more meanings, which are presented as follows:

- Fraud is the sum of irregularities and illegal actions made with the intention to cheat.

- Fraud is any type of activity or voluntarily omitting the usage or the presentation of incorrect, false, or incomplete reports, minutes, or financial statements.

- Fraud can be the act of hiding information by violating a specific duty and/or abduction of funds from the initial purpose for which they were granted.

In practice, all the elements related to disorders or frauds are important, and they represent a problem both for the managers and for the internal auditors.

From the above explanation, a question arises pertaining to how to solve these risky subjects. How can a company's system fight and overcome these disorders? What can an internal auditing department do to detect and improve these vulnerable weak points to hedge against misuses? The internal auditing departments prepare independent 


\section{Articles}

and objective auditing reports by considering weak points and measures to strengthen them at the end of their activities. As Schelker (2008) reported, internal auditing serves as "watchdogs" of shareholders to develop transparency, eliminate misappropriation, fraud, corruption, and the misuse of company assets. After preparation, they submit these reports to the attention of the boards of directors. These reports are revealed to the review of the shareholders to enable them to evaluate the internal control system of the entity. Additionally, we can see from Coram, Ferguson, and Moroney (2008) that recent well-publicized frauds have affected the work of the external financial statement auditor.

We can name disorders, irregularities, weaknesses, and frauds briefly "weak points".

\subsection{The function of an internal auditing department on the detection of weak points}

Guredin (1996) reveals in his review of the literature on the role of internal auditing activities in the governance of an organization that most of the research on the effective internal audit department's function has a connection with the perceptions of the external auditing and if the external auditing utilizes the works of internal auditing. Chamber (2010) states that internal auditing enables companies to be in charge of more profitable fields by eliminating risky points. When an internal auditing department detects a weak point, it establishes a control mechanism to block the possible future misuses. If it catches any weak point, it analyzes the system to realize which points of the internal control system have failed and what has made it possible for the disorders to occur. By this reporting, an internal auditing department not only documents the weak points but also submits the solutions. The internal auditing reports have been concluded by considering auditing techniques and methods, company
The Effects of the Qualitative Parameters of Internal Auditing Works on the Preferences of Investment Funds' Analysts

procedures, domestic legislations, and investigative techniques.

Principally, these reports also consider process efficiency and the points below:

- Defining where the weak points are and analyzing solutions for the future risks.

- Establishing preventive and detective measurements to eliminate the weak points.

- Recommending systems to strengthen the process.

When the management of a company finds out from the internal audit report the existence of possible fraud, the action must be an immediate investigation on the cause by using internal control instruments or inspections, if they exist or to appoint a commission to the related department for resolving it. On the other hand, internal auditing is not a one time job, but it is a continuing activity in an organization (Chambers, 2010).

\subsection{The responsibilities of internal auditing departments for the detection, prevention, and the investigation of the weak points}

An internal control system is an essential tool for the continuation of an organization. Karagiorgos et al. (2009) reveal that it is a critical department in a company. Suleiman (2015) states that the importance of an internal auditing department in organizations is growing because of the increasing trends of frauds and other irregularities. The responsibilities of an internal auditing department regarding the subject of taking measures against disorders are:

a) elaborating the plans of action through measures for reducing the risks of weak points,

b) structuring the procedures of the internal control system for reducing risks,

c) elaborating a plan of the future steps to be followed in case a fraud has been 


\section{Articles}

reported or detected,

d) promoting of ethic principles for the company,

e) designing and maintaining an effective internal control system that will add values for the prevention the risks.

After the internal auditing report is presented, the management of the company would apply the recommendations of the report, and the company would have the following:

a) Policies, practices, and procedures to control the activities and ensure the protection of company assets against risks,

b) Written rules that describe the forbidden activities and the measures to be taken in case the established rules are broken;

c) Procedures and rules of authorized persons for all operations,

d) Recommendations for establishing and amending the internal control system in order to discourage frauds.

\section{Background, data collection, and estimation methodology}

\subsection{Background}

Sharma (2004) identified fraud as the misappropriation of company assets. It can be expected that shareholders require from the managers that the assets of the company which they invested should be utilized or consumed to the maximum level of efficiency. Investors believe that only in this condition they can get the maximum return for their investment in the company. The financial ratios may provide very competitive results to satisfy the shareholders. On the other hand, investors may still search which additional tools can be utilized to analyze whether it is possible to get more returns than the satisfactory parameters provided.

Of course, investors may reach lots of tools to satisfy their curiosity (Davidson, MacKinnon, 1993). For example, they can get consultancy service from external auditors, appraisers, evaluators, etc. to conclude various types of reports which includes comparative statements (horizontal analysis), common size statements (vertical analysis), trend analysis, ratio analysis, cash flow analysis, and so on.

As one of the most functional governance tools, IARs are also very useful for observing if the company assets are utilized with maximum efficiency and if there are any weak points for any type of risk of fraudulent actions. For example, Wallace (1984) indicated that relying on the internal department's efficiency provides $10 \%$ cost reduction of auditing fee. External auditors focus on fraud investigation by analyzing financial statements, while internal auditing analyzes in detail how the assets of the company are consumed (Chadwick, 2000). Internal auditing analysis is not only the financial statements prepared by financial affairs departments but also all the assets of a company. Internal auditors should have a lot of considerable responsibilities, quality requirements, and experienced knowledge to reach their target regarding this mission of identifying if there is a misappropriation or not.

\subsection{Research hypothesis}

We prepared the questionnaire to accumulate data what can be the perceptions of the investors as far as performance of internal auditing department is concerned and in which direction this perception may affect their investment decisions.

The questionnaire is arranged according to the following alternatives:

If I know that there is an internal auditing department in a company:

My confidence to invest in that company may be affected if:

(i) The internal auditing process and report is concluded by experienced auditors (1 to 5); 


\section{Articles}

(ii) The internal auditing work is processed objectively (1 to 5 );

(iii) The internal auditors act independently during the auditing process (1 to 5);

(iv) The content of financial reports and their disclosures prepared by the accounting department (1 to 5).

At first glance, it may be thought that the reader cannot understand why exactly these three qualitative features were chosen for investigation: experience, objectivity and independence. It is hard to believe that anyone anywhere has ever stated that these qualitative features are not important to the internal audit function/system from the investors' viewpoint. Finally, all these three features are part of the core principles for the professional practice of internal auditing. But the idea is not arguing that these features are valuable or not for an investor. The hypothesis tries to understand the effects of these three points on the decision process for investing in a company. In other words, in addition to financial statements, how these three elements affect the decision of the investors.

This article tries to propose a theory whether investor confidence would be affected by these cross choices and whether a correlation exists between the investment experts' preferences and having knowledge if a company has an internal auditing department and the quality of the internal auditing process. An attempt was made to propose the theory whether the knowledge of the existence of an internal control environment and its quality within a company is strongly associated with an investor's preferences at the time of investing in a company. Or, investors' preferences are structured by paying attention only to the financial reports and their disclosures produced by the accounting department.

\subsection{Data collection and classification}

The data has been collected from the participants mentioned in table 1 below. The
The Effects of the Qualitative Parameters of Internal Auditing Works on the Preferences of Investment Funds' Analysts

target of the survey and the questionnaire simply distributed to the participants who work in investment funds to identify the perceptions of the participants of the effect of qualitative criteria of IARs in the eyes of investors. Out of 143 copies of the questionnaire, 66 were returned $(46 \%)$ by the participants who have different levels of positions in investment funds companies as manager, expert, and assistant. As far as the unreturned questionnaires are concerned, there is no noticeable accumulation from the positions of the participants because the rates of return are very close.

Table 1. Definitions of the participants

\begin{tabular}{|l|r|r|r|r|}
\hline Questionnaire & Managers & Experts & Assisstants & Total \\
\hline Returned & 5 & 21 & 40 & 66 \\
Unreturned & 6 & 23 & 48 & 77 \\
\hline Total & 11 & $\mathbf{4 4}$ & $\mathbf{8 8}$ & $\mathbf{1 4 3}$ \\
\hline Rate of return & $\mathbf{4 5 \%}$ & $\mathbf{4 8 \%}$ & $\mathbf{4 5 \%}$ & $\mathbf{4 6 \%}$ \\
\hline
\end{tabular}

The questionnaire was arranged to get the primary source of data collection from the participants. The four questions in the questionnaire were sent to the participants, and they were required to mark their perceptions by considering their thoughts from 1 to 5 by utilizing the Likert summated rating scale. The choice from 1 to 5 is structured as follows: 1 = strongly agree, 2 = agree, 3 = neutral, 4= disagree, 5 = strongly disagree. The answers from the participants are analyzed for having a conclusion about the hypothesis of this research. Table 1, above, provides the number and positions of the returned and unreturned questionnaire by the participants. To enable the participants to have an equal chance of appearance, random sampling was utilized.

The collected data from the participants were classified on the basis of the following: 


\section{Articles}

Table 2. Documenting the preferences of the investors

\begin{tabular}{|c|l|c|}
\hline $\mathbf{S} / \mathbf{N}$ & \multicolumn{1}{|c|}{ Choices } & $\begin{array}{c}\text { Evaluate } \\
\mathbf{1} \text { to } \mathbf{5}\end{array}$ \\
\hline 1 & $\begin{array}{l}\text { The internal auditing process and report is } \\
\text { concluded by experienced auditors }\end{array}$ & \\
\hline 2 & $\begin{array}{l}\text { The internal auditing works is processed } \\
\text { objectively }\end{array}$ & \\
\hline 3 & $\begin{array}{l}\text { The internal auditors act independently } \\
\text { during the auditing process }\end{array}$ & \\
\hline
\end{tabular}

\subsection{Data analysis techniques}

For analyzing the returned questionnaire, the following data analysis techniques have been used:

3.4.1. Descriptive Statistic Analysis has been utilized to determine the thoughts of the participants on the basis of percentages, mean, median, mode, and standard deviation.

$\circ$ Proportion $=f / N$ and percentage $=f / N * 100$

$\circ$ Mean $>4.0$ as the minimum and the minimum expected value for mode and median is 4.0

3.4.2. The Chi-Square Analysis was utilized for testing the hypotheses according to the answers of the participants to evaluate if there is a considerable difference between the means of the answers. The rejection condition of the hypothesis is 95\% confidence of alpha with - $\alpha 0.05$ in case the results of the Chi-Square statistics are more than the critical value of Chi-Square. The null hypothesis would be accepted while it is at a $95 \%$ level of confidence (alpha - a 0.05) in case the results of the Chi-Square statistics are less than the critical value of Chi-Square.

3.4.3. Mann-Whitney analysis was also utilized to evaluate if there were significant differences between the parameters of the two groups. The results of the analysis are presented in the respective part.

\section{Empirical findings}

Table 3 presents the spread of preferences of the participants according to the distributed questionnaire in table 2. The table reveals the fact that the composition of the differences among the rows does not have significant variations. That means that the thoughts of the participants to the three categories of the choices, namely Experienced Internal Auditors (EIA), Processed Objectively (PO), and Independent Internal Auditing Process (IIAP), have almost the same strengths in the minds of the investment fund employees.

Table 3. The number of the preferences of the participants

\begin{tabular}{|l|c|c|c|c|c|c|c|}
\hline & $\begin{array}{c}\text { Strongly } \\
\text { agree } \\
\text { (1) }\end{array}$ & $\begin{array}{c}\text { Agree } \\
\text { (2) }\end{array}$ & $\begin{array}{c}\text { Neutral } \\
\text { (3) }\end{array}$ & $\begin{array}{c}\text { Disagree } \\
\text { (4) }\end{array}$ & $\begin{array}{c}\text { Strongly } \\
\text { Disagree } \\
\text { (5) }\end{array}$ & $\begin{array}{c}\text { N } \\
\text { Valid }\end{array}$ & $\begin{array}{c}\text { N } \\
\text { Missing }\end{array}$ \\
\hline $\begin{array}{l}\text { The internal auditing process and report are concluded by } \\
\text { Experienced Internal Auditors (EIA) }\end{array}$ & 16 & 24 & 20 & 4 & 2 & 66 & 0 \\
\hline The internal auditing works is Processed Objectively (P0) & 17 & 22 & 20 & 5 & 2 & 66 & 0 \\
\hline $\begin{array}{l}\text { The internal auditors act Independently during the Internal } \\
\text { Auditing Process (IIAP) }\end{array}$ & 14 & 26 & 19 & 5 & 2 & 66 & 0 \\
\hline
\end{tabular}

To investigate the thoughts of the investors about internal auditing work from different angles, we collected data, shown in table 3 , with different statistical tests and methods. The results of the statistical studies are presented in the following sections. The unique target was to document if there is an association between the quality perspectives of the products of internal auditing departments and the thoughts of the investors.

Among lots of difficulties in testing investor preferences, the theory of this document tried to understand how investors consider the work 
of internal auditing departments. In order not to have a segment effect of the participants, the companies were chosen from similar sectors and business volume. For the purpose of this study, the participants were required to choose from the different levels of grades, from 1 to 5 . The 66 answers from investment fund companies in the sample above were deliberately used to see the perspectives of the participants.

Table 4. The Descriptive Statistics on Determining the Investors Considerations on the Value of Internal Auditing Quality

\begin{tabular}{|c|c|c|c|}
\hline & EIA & PO & IIAP \\
\hline \multicolumn{4}{|c|}{ Panel 1. Summary statistics for invester preferences by considering Internal Auditing Works } \\
\hline Mean & 3.727 & 3.712 & 3.682 \\
\hline Standard Error & 0.123 & 0.127 & 0.122 \\
\hline Median & 4 & 4 & 4 \\
\hline Mode & 4 & 4 & 4 \\
\hline Standard Deviation & 1.001 & 1.034 & 0.995 \\
\hline Sample Variance & 1.001 & 1.070 & 0.990 \\
\hline Kurtosis & 0.120 & -0.147 & 0.132 \\
\hline Skewness & -0.561 & -0.507 & -0.572 \\
\hline Range & 4 & 4 & 4 \\
\hline Minimum & 1 & 1 & 1 \\
\hline Maximum & 5 & 5 & 5 \\
\hline Sum & 246 & 245 & 243 \\
\hline Count & 66 & 66 & 66 \\
\hline
\end{tabular}

Panel 2. Correlation matrix for invester preferences by considering Internal Auditing Works

\begin{tabular}{lccc}
\hline & EIA & P0 & IIAP \\
\hline EIA & 1 & & \\
\hline P0 & 0.936 & 1 & \\
\hline IIAP & 0.947 & 0.971 & 1 \\
\hline
\end{tabular}

Table 4 above reveals the outcomes of descriptive statistics for various alternatives of variables, EIA, PO, and IIAP. The statistics explain that the answers of 66 participants were reflected in the three choices. It can be clearly observed that Panel 1 presents the summary of descriptive statistics for EIA, $\mathrm{PO}$, and IIAP. Panel 2 reveals the correlation matrix among the three variables, EIA, PO, and IIAP.

We can read from Panel 1 that there are no significant differences among the three alternative evaluation subjects. The means, medians, and modes of EIA, PO, and IIA are very close to each other. More specifically;

- The means are between 3.68 and 3.73, and the difference, among these three choices, is insignificant, $1.36 \%$.

- The medians, modes, and ranges present simple numerical orders for three variables.

- The standard deviations and sample variances show a very close environment to 1 . 


\section{Articles}

- The Skewness results document that the amount and direction of skew (the departing level of the data from horizontal symmetry).

- The kurtosis results define that there is no sharp settlement on the tails of the distribution of the preferences of the contributors.

The correlation matrix also reveals that there is a positive correlation, and that confirms that the data were scattered in a positive direction as it is shown in Figure 1.

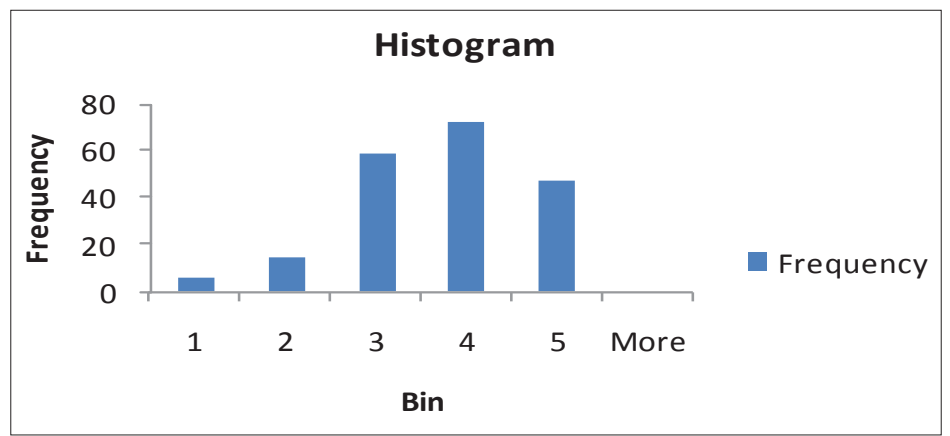

Figure 1. Histogram graph of the preferences

Table 5. The Chi-square Analysis for Determining the Investors Considerations on the Value of Internal Auditing Quality

\begin{tabular}{|c|l|r|r|r|r|r|}
\hline & & $\begin{array}{c}\text { Strongly agree } \\
\mathbf{( 1 )}\end{array}$ & $\begin{array}{c}\text { Agree } \\
\mathbf{( 2 )}\end{array}$ & \multicolumn{1}{c|}{$\begin{array}{c}\text { Neutral } \\
\mathbf{( 3 )}\end{array}$} & $\begin{array}{c}\text { Disagree } \\
\mathbf{( 4 )}\end{array}$ & $\begin{array}{c}\text { Strongly Disagree } \\
\mathbf{( 5 )}\end{array}$ \\
\hline \multirow{3}{*}{ EIA } & Chi-Square & 15.66666667 & 24 & 19.6666667 & 4.6666666667 & 2 \\
& Df & 4.6655 & 4.6655 & 4.6655 & 4.6655 & 4.6655 \\
& Asymp. Sig. & .000 & .000 & .000 & .000 & .000 \\
\hline \multirow{3}{*}{ PO } & Chi-Square & 15.66666667 & 24 & 19.6666667 & 4.666666667 & 2 \\
& Df & 6.7194 & 6.7194 & 6.7194 & 6.7194 & 6.7194 \\
& Asymp. Sig. & .000 & .000 & .000 & .000 & .000 \\
\hline \multirow{3}{*}{ IIAP } & Chi-Square & 15.66666667 & 24 & 19.6666667 & 4.666666667 & 2 \\
& Df & 3.9331 & 3.9331 & 3.9331 & 3.9331 & 3.9331 \\
& Asymp. Sig. & .000 & .000 & .000 & .000 & .000 \\
\hline
\end{tabular}

We can observe from the chi-square outcomes the association between investor confidence and EIA, PO, and IIAP. The test confirms that the preferences of investors were unevenly distributed among the participants $(p=.009)$. There was no statistically considerable difference between the auditing quality factors on the part of the investment fund employees $(p=.009)$. 


\section{Regression Analysis}

Table 6.1. Regression Statistics between EIA and PO

SUMMARY OUTPUT

\begin{tabular}{lr}
\hline Regression Statistics Between EIA and PO \\
\hline Multiple R & 0.9635 \\
R Square & 0.9283 \\
Adjusted R Square & 0.9272 \\
Standatd Error & 0.2700 \\
Observations & 66 \\
\hline
\end{tabular}

ANOVA

\begin{tabular}{lrrrrr}
\hline & \multicolumn{1}{c}{$\boldsymbol{d f}$} & \multicolumn{1}{c}{$\boldsymbol{S} \boldsymbol{S}$} & \multicolumn{1}{c}{$\boldsymbol{M S}$} & \multicolumn{1}{c}{$\boldsymbol{F}$} & \multicolumn{1}{c}{ Significance $\boldsymbol{F}$} \\
\hline Regression & 1 & 60.4254 & 60.4254 & 828.8977 & 0.0000 \\
Residual & 64 & 4.6655 & 0.0729 & & \\
Total & 65 & 65.0909 & & & \\
\hline
\end{tabular}

\begin{tabular}{lrrrrrrrr}
\hline & Coefficients & \multicolumn{1}{c}{ Standard Error } & \multicolumn{1}{c}{ Stat } & P-value & Lower 95\% & Upper 95\% & Lower 95.0\% & Upper 95.0\% \\
\hline Intercept & 0.2667 & 0.1247 & 2.1388 & 0.0363 & 0.0176 & 0.5159 & 0.0176 & 0.5159 \\
P0 & 0.9322 & 0.0324 & 28.7906 & 0.0000 & 0.8675 & 0.9969 & 0.8675 & 0.9969 \\
\hline
\end{tabular}

We can infer from Table 6.1 that;

- There is a strong linear relationship between EIA and PO (Multiple $\mathrm{R}=0.9635$ ).

- Almost $93 \%$ of the preferences between EIA and PO fit (R Square $=0.9283$,
Adjusted R Square 0.9272).

- The standard error is very close to the regression coefficient.

- Linear regression equation confirms that the association between EIA and PO is considerable $\left(y=0.2667+0.9322^{*} x\right)$

Table 6.2. Regression Statistics between EIA and IIAP

SUMMARY OUTPUT

\begin{tabular}{lr}
\hline Regression Statistics Between EIA and IIAP \\
\hline Multiple R & 0.9470 \\
R Square & 0.8968 \\
Adjusted R Square & 0.8952 \\
Standatd Error & 0.3240 \\
Observations & 66 \\
\hline
\end{tabular}

ANOVA

\begin{tabular}{lrrrrr}
\hline & \multicolumn{1}{c}{$\boldsymbol{d f}$} & \multicolumn{1}{c}{$\boldsymbol{S} \boldsymbol{T}$} & \multicolumn{1}{c}{$\boldsymbol{M S}$} & \multicolumn{1}{c}{$\boldsymbol{F}$} & Significance $\boldsymbol{F}$ \\
\hline Regression & 1 & 58.3715 & 58.3715 & 555.9656 & 0.0000 \\
Residual & 64 & 6.7194 & 0.1050 & & \\
Total & 65 & 65.0909 & & & \\
\hline
\end{tabular}

\begin{tabular}{lrrrrrrrr}
\hline & Coefficients & \multicolumn{1}{c}{ Standard Error } & \multicolumn{1}{c}{$\boldsymbol{t}$ Stat } & P-value & Lower 95\% & Upper 95\% & Lower 95.0\% & Upper 95.0\% \\
\hline Intercept & 0.2198 & 0.1540 & 1.4271 & 0.1584 & -0.0879 & 0.5275 & -0.0879 & 0.5275 \\
IIAP & 0.9527 & 0.0404 & 23.5789 & 0.0000 & 0.8719 & 1.0334 & 0.8719 & 1.0334 \\
\hline
\end{tabular}

Table 6.2 shows quite similar results to Table 6.1.

We can understand from Table 6.2 that:
- Although not as strong as between EIA and $\mathrm{PO}$, there is also a strong linear relationship between EIA and IIAP 


\section{Articles}

(Multiple $\mathrm{R}=0.9470$ ).

- Almost $90 \%$ of the preferences between EIA and IIAP fit (R Square $=0.8968$, Adjusted R Square 0.8952).

- The standard error is very close to the regression coefficient.

- Linear regression equation confirms that the association between EIA and IIAP is considerable $\left(y=0.2198+0.9527^{*} x\right)$

Table 6.3. Regression Statistics between PO and IIAP

SUMMARY OUTPUT

\begin{tabular}{lr}
\hline Regression Statistics Between PO and IIAP \\
\hline Multiple R & 0.9713 \\
R Square & 0.9434 \\
Adjusted R Square & 0.9425 \\
Standatd Error & 0.2479 \\
Observations & 66 \\
\hline
\end{tabular}

ANOVA

\begin{tabular}{lrrrrr}
\hline & \multicolumn{1}{c}{$\boldsymbol{d f}$} & \multicolumn{1}{c}{$\boldsymbol{S} \boldsymbol{c}$} & \multicolumn{1}{c}{$\boldsymbol{M S}$} & \multicolumn{1}{c}{$\boldsymbol{F}$} & Significance $\boldsymbol{F}$ \\
\hline Regression & 1 & 65.5972 & 65.5972 & 1067.4083 & 0.0000 \\
Residual & 64 & 3.9331 & 0.0615 & & \\
Total & 65 & 69.5303 & & & \\
\hline
\end{tabular}

\begin{tabular}{lrrrrrrrr}
\hline & Coefficients & \multicolumn{1}{c}{ Standard Error } & \multicolumn{1}{c}{ Stat } & P-value & Lower 95\% & Upper 95\% & Lower 95.0\% & Upper 95.0\% \\
\hline Intercept & -0.0061 & 0.1178 & -0.0520 & 0.9587 & -0.2415 & 0.2293 & -0.2415 & 0.2293 \\
IIAP & 1.0099 & 0.0309 & 32.6712 & 0.0000 & 0.9481 & 1.0716 & 0.9481 & 1.0716 \\
\hline
\end{tabular}

Table 6.3 also presents pretty close results as shown in Table 6.1 and Table 6.2.

We can understand from Table 6.3 that:

- There is a strong linear relationship between PO and IIAP (Multiple $\mathrm{R}=0.9713$ ).

- Almost 94\% of the preferences between $\mathrm{PO}$ and IIAP fit (R Square $=0.9434$, Adjusted R Square 0.9425).

- The standard error is very close to the regression coefficient.

- Linear regression equation confirms that the association between PO and IIAP is considerable $\left(y=-0.0061+1.0099^{*} x\right)$

\section{Summary of Empirical findings}

It can be summarized from the descriptive statistics, chi-square tests, and regression analysis that the representatives of investment funds revealed their opinions about the evaluation of the quality of IARs. From the results of the tests, we can summarize that: a) The internal auditing process and report are concluded by Experienced Internal Auditors (EIA) is highly important for the investment fund expert. It is revealed in the tests if an internal auditing report is prepared by experienced internal auditors (EIA), it is just considered as a positive tool in the investment process, but not fully effective on the level of investment decision (mean 3.727, St. dev. 1.001, Kurtosis 0.120, and Skewness -0.561).

b) The internal auditing works are Processed Objectively (PO) is assessed as a significant point (not as significant as EIA) for the managers, experts, and assistants of investment funds. $P O$ is an effective point in the process of investment decisions (mean 3.712, St. dev. 1.034, Kurtosis -0.147, and Skewness -0.507).

c) The internal auditors act Independently during the Internal Auditing Process (IIAP) is assessed as a considerable issue (not as significant as EIA and PO) 


\section{Articles}

for the participants in the questionnaire from the investment funds. IIAP is taken into consideration as a subject during the process of investment decisions (mean 3.682, St. dev. 0.995, Kurtosis 0.132, and Skewness -0.572).

If we sum up, the investment fund decision-makers do not point out the IAR as a sine qua non in their working process. The experience of internal auditors (EIA), the objectivity of internal auditing works (PO), and the independence of internal auditors (IIAR) are considered on the level of valuable data to be taken into account, but they do not say that these three data are on the level of a must.

\section{Conclusion}

This paper evaluates the effectiveness of the internal audit process in the eyes of the managers, experts, and assistants of investment fund organizations. Since each interest group has different expectations from an organization, its tools to evaluate the organization can be different. Sometimes, a report can be an essential document for one interest group, but for another interest group, it can occupy a secondary position. The importance of an internal control system is growing as the complexity of the organization is greater (Guredin, 1996).

This conclusion justifies that the experience of internal auditors, the objectivity of the internal auditing process, and the independence of internal auditors are appreciated by the investment decisionmakers. On the other hand, this appreciation is not on the level of sine qua non. In other words, it can be revealed that the utilization of internal auditing services is being rewarded by the teams of investment fund companies.

It is argued that the hypothesis of this document suggests that the function of internal auditing departments is perceived as vital data for the mechanism of investment decisions
The Effects of the Qualitative Parameters of Internal Auditing Works on the Preferences of Investment Funds' Analysts

in investment fund companies. There may be several possible reasons for this result, and these reasons can be a subject of further research studies. As a point, Lowe et al. (1999), James (2003) and Carey et al. (2006) say that financial statement users think that there is no considerable difference between the reports of internal auditing or external auditing. Holt et al. (2009) state that IAR increases the confidence of investors in a company. For example, IARs may be taken into account just as a governance tool for the board of directors. Or, there may be key issues such as financial reports, and their disclosures, which are processed by the financial affairs department and approved by external auditors. Lastly, different financial ratios or lots of production parameters may be essential in the eyes of investment fund experts.

\section{References}

Abbott, L. J., Parker, S., and Park, Y. (2000), The effects of audit committee activity and independence on corporate fraud, Managerial Finance, 26, 55-67.

Abbott, L. J., Parker, S., Peters, G. F., and Rama, D. V. (2007), Corporate governance, audit quality and the Sarbanes-Oxley Act: evidence from internal audit outsourcing, Accounting Review, 82, 803-835.

Beasley, M. S., Carcello, J. V., Hermanson, D. R., and Lapides, P. D. (2000), Fraudulent Financial reporting: Consideration of industry traits and corporate governance mechanisms, Accounting Horizons, 14, 441-454.

Carey, P., Tanewski, G., and Simnett, R. (2000), Voluntary demand for internal and external auditing by family businesses, Auditing: A Journal of Practice and Theory, 19, 37-51.

Chadwick, W. E., (2000), Keeping internal auditing in-house, International Auditor 57, 88.

Chambers, A. (2010), Implementing an Effective Internal Control System. Finance. 


\section{Articles}

www.qfnance.com/auditing-best.practice/ implementing An Effective Internal Controls. (Retrieved 5/12/2010).

Coram, P., Ferguson, and C., Moroney, R. (2008), The Value of Internal Audit in

Fraud Detection, Accounting and Finance, 48 (2008) 543-559

Davidson, R., and MacKinnon, J.G. (1993), Estimation and Inference in Econometrics, New York: Oxford University Press, p. 708

Dunn, J. (1996), Auditing: Theory and Practice. London: Prentice-Hall, 2nd Edition.

Guredin, E. (1996). Denetim (Auditing), Beta Basım Yayım, Ed. 10.

Holt, T.P. and DeZoort, T. (2009), The Effects of Internal Audit Report Disclosure on Investor Confidence and Investment Decisions, International Journal of Auditing, Int. J. Audit. 13: 61-77 (2009)

James, K. L. (2003), The effects of internal audit structure on perceived financial statement fraud prevention, Accounting Horizons, 17, 315-327.

Karagiorgos, T., Drogalas, G., Gotzamanis, E., and Tampakoudis, I. (2009). The Contribution of Internal Auditing to Management. International Journal of Management Research and Technology, Vol. 3, No. 2, Serials Publications, pp. 417-427.

Lowe, D. J., Geiger, M. A., and Pany, K. (1999), The effects of internal audit outsourcing on perceived external auditor independence, Auditing: A Journal of Practice and Theory, 18, 7-26.

Millichamp, A.H (2002), Auditing: An Instructional Manual for Accounting Students, London: DP Publishers.

Schelker, M. ( 2008), Public Auditors: Empirical Evidence from the US States. University of Fribourg, Switzerland, and CREMA, available on-line at http://papers.ssrn.com/sol3/papers. cfm?abstract_id=957528.
Sharma, V. D. (2004), Board of director characteristics, institutional ownership, and fraud: evidence from Australia, Auditing: $A$ Journal of Practice and Theory, 23, 105-117.

Suleiman, N. (2015), Internal Audit and the Effectiveness and Efficiency of Operations in Hospitals, Proceedings of 11th International Business and Social Science Research Conference, January 8-9, 2015, Crowne Plaza Hotel, Dubai, UAE. ISBN: 978-1-922069-70-2

Vincent, M.O., Barry, N.W., James, S.G. and Henry, R.J. (1999), Montgomery's Auditing. 12th Edition, Continuing Professional Education Version. USA: Price Water House Coopers LLP.

Wallace, W. (1984), Internal auditors can cut outside CPA costs. Harvard Business Review, 62:2, 16-20.

\section{List of tables:}

Table 1. Definitions of the participants

Table 2. Documenting the preferences of the investors

Table 3. The number of the preferences of the participants

Table 4. The Descriptive Statistics on Determining the Investors Considerations on the Value of Internal Auditing Quality

Table 5. The Chi-square Analysis for Determining the Investors Considerations on the Value of Internal Auditing Quality

Table 6.1. Regression Statistics between EIA and $\mathrm{PO}$

Table 6.2. Regression Statistics between EIA and IIAP

Table 6.3. Regression Statistics between PO and IIAP

\section{List of figures:}

Figure 1. Histogram graph of the preferences 